\title{
Enriching Stakeholder Theory: Student Identity of Higher Education
}

\author{
Joseph W. C. Lau \\ Hong Kong Institute of Vocational Education, Hong Kong, China \\ Email: drjosephlau@zoho.com
}

Received 18 October 2014; revised 29 November 2014; accepted 16 December 2014

Copyright (C) 2014 by author and Scientific Research Publishing Inc.

This work is licensed under the Creative Commons Attribution International License (CC BY).

http://creativecommons.org/licenses/by/4.0/

c) (i)

\begin{abstract}
While students commonly assume the identity of being key stakeholders of higher education, the present article explores the possible complications stemmed from such key identity. Stakeholder theory has its strengths attributed by its conceptual breath and versatility; the limits of the theory arise for the same merit. Making reference to the theory with no restrains leads reasonably to the conclusion that the educational institute is unwilling to take measure closely to the long term effect, tangible or intangible, of such approach. Providing multiple perspectives on the identity of students are observed, an enrichment of stakeholder theory catering student identity is necessary.
\end{abstract}

\section{Keywords}

Stakeholders, Stakeholder Theory, Student Identity, Higher Education

\section{Introduction}

Students are key stakeholders of higher education for two main reasons: First, the success of a higher institute depends upon students as the constituent group. Second, students have inter alia an interest and expectation in the quality of education being provided [1]. The present article aims to examine how the identity of students can be defined using stakeholder theory as a standpoint. In specific, while students assume the identity of being key stakeholders of higher education, the present article explores the possible complications stemmed from such key identity. In this light, the article will first present a general analysis and critique of stakeholder theory. Next, the article will make comparison of three journal articles in their views of student identity. The article sees that enrichment of stakeholder theory catering student identity is necessary, and at the end, recommendations will be made on further direction of research.

\section{Stakeholder Theory}

In his seminal work on stakeholder theory, Freeman [2] laid the groundwork for the development of the theory. 
Freeman [2] chose the word "stakeholder" as opposed to the traditional term "stockholder" which is more inclined towards an economic point of view of organization. Since the traditional strategic frameworks had been less effective against a more complex business environment, Freeman offered a way to redefine the organization and explain the relationship of the firm to its external environment as well as its behavior within this environment. Furthermore, Freeman provided a way to conceptualize an organization by graphically modeled the concept of stakeholders as impacting actors on the firm and on whom the firm impacts.

Stakeholder theory has its strengths and limits. The strength of the theory lies in its nature of being a completing theory of the firm for explaining and predicting organizational function in regards to stakeholder influences [3]. Besides, based on the work of Donaldson and Preston [4], it is understood that there are four central theses scaffolding the salient functions of the theory: First, the theory is descriptive as it offers a model of how a firm operates in relation with its constituencies. Second, the theory is instrumental as it offers a tool to evaluate the achievements of various corporate governance goals with the practice of stakeholder management. Third, the theory is normative as it offers an ethical groundwork for how a firm should operate with respect to the welfare of stakeholders being considered to be intrinsically valuable. Forth, the theory is managerial as it recommends practices to management which prompts attention to the interest of all its legitimate stakeholders.

While the theory has its strengths attributed by its conceptual breath and versatility, the limits of the theory arise for exactly the same merit. The fact that the theory carries myriad connotations and interpretation makes the theory shy of being specific. The lack of specificity means that advocates of the theory may carry out all the good deeds, but the effects are less likely to be optimal unless these deeds are "dressed up" with more accurate data and more precise delineation. As Key [5] comments, the theory fails to meet the requirement of scientific theory, and modification or enrichment of the theory is necessary. At the same time, while the theory has a strong ethical connection to business operation, it is highly controversial as to what serves as "right", "just", "fair" or "moral" along with other prescriptive notions for stakeholders, non-stakeholders, shareholders or an organization. Issues also arise when it comes to who gets the authority to make decisions on various ethical dilemmas and to what extend and degree should a business firm take ethical issues into account when carrying out its business.

Perhaps the most serious problem with the theory roots in the identity of stakeholders. That is, the theory on one hand talks about the fact that a firm contains all these normative or derivative constituency groups, on the other hand, the theory does not have an inclination to address who these groups actually are and the entailed relationships a firm should be having with them. As Fassin [6] pinpoints, the theory tends to be over-simplified where more complex dynamics of relationships are observed in a firm. Fassin [6] further argues that the most obvious "shortcomings" emerge from the identity problem of stakeholders which comprises at least two issues: First, stakeholders can have heterogeneous roles, i.e., the roles of stakeholders could be debatable based on how their identities are defined. Second, stakeholders' inter-dependence and reciprocity may not be as equal and direct as the theory suggest; it is not uncommon to see change of relationship when factors determining such relationship change.

The results of the problem of specificity, particularly identity problem, with stakeholder theory are: First, strategies with the stakeholders are immeasurable as there is too much uncertainty and unpredictability underlying the various domains of the relationships. Besides, when an inconsistency of paradigms exists largely due to the way how different advocates of the theory tend to have different positivist views of the dynamics, it would be contestable in any case once any consensus is made as to, say, what is the best solution or response to the situation. Thirdly, since there is a lack of justificatory framework regarding stakeholder identity and legitimacy, advocates of theory could also take any position they wish in their hands which result in the danger of violating a firm's core business mission and interest due to arbitrary interpretation of, for example, what intrinsic values stakeholders are constitutive of, or how much should a firm "give in" to stakeholders in meeting their expectations, in some instances giving in for the sake of doing so regardless of what the nature of these expectations are. Finally, the fundamental long term effect of taking the theory with no restrains, particularly, when defining the identity of a firm's core stakeholder hastily and scruple afterwards at nothing lead reasonably to the conclusion that the firm is either being complacent in their business by adopting a general yet simplistic approach for management, or it is simply not willing to take measure closely to the long term effect, tangible or intangible, of such approach.

It is uncontroversial that the success of higher education depends upon students being as core stakeholders; nevertheless, what is this supposed to mean? Higher education management on one hand could adopt stake- 
holder theory and define the identity of students at will, but because the theory provides only a preliminary step towards understanding the importance of relationship endeavor and carrying out the business with a certain degree of ethical awareness, it is insufficient and often ill-advised to just set the tone with no further consideration. Integrity for higher education is called for because ethically higher education is per se a core stakeholder of the society and holds dyadic liabilities. Vigilance for higher education is called for because the cost of a blurry differentiation between a higher institute and a business organization means there are likely to be conflicting goals. The spectrum of reality lies between higher education being the traditional cradle of wisdom and knowledge, to a "market" where a supply chain of educational service prevails. And while a good number of school management bodies and scholars are boldly accepting and abiding to the "marketization" of higher education, hence, cohering students' identities of core stakeholders with customers, it would be fair and reasonable to reflect whether exploring the potential of different identities possibly assumed by students is worthy.

\section{Student Identity}

To illustrate the potential of students assuming different identities, three articles are reviewed: Seeman and O’Hara; Singh; and Sperlich and Spraul [7]-[9]. Seeman and O'Hara [7] view students of higher education as customers and explore the application of customer relationship management (CRM) in higher education setting. In the article, Seeman and O'Hara [7] observe the development and implementation of a CRM project in a state community college and evaluate its effects. Seeman and O'Hara [7] conclude that benefits are realized by implementing CRM which included a student-centric focus, improved customer data and process management, as well as increased student loyalty and satisfaction with the college's programs and services. In their research, Seeman and O'Hara [7] also conducted semi-structured interviews with individuals involved with the implementation of a statewide CIS system; student support personnel were additionally interviewed as well.

The strengths of Seeman and O'Hara's article lies in two aspects: First, data were collected from a case study which enhances the feasibility of replicating the implementation of CRM in other higher education setting. Second, the study contained semi-structured interviews which provide empirical evidence to the argument. Despite the strengths, the sample size of one case has weak external validity. Besides, the article could have a deeper exploration of student identity by conducting direct interviews or questionnaires surveys with students.

In terms of stakeholder theory, the formulation of the identity that students are being customers means the followings: First, a market would naturally be established and all other stakeholders would have to be subject to and act according with the environment of such establishment. Second, the success of management is primarily measured by marketing criteria as to whether or not it has attracted enough customers, customers' satisfaction and so forth, and managing tools such as CRM as recommended by Seeman and O'Hara [7] is plausible. Third, the ethical groundwork for operating higher education is oriented towards the welfare of various stakeholders existing in the market of higher education wherein customer's welfare is indisputably a priority. Forth, higher education management would be more eager to proclaim a readiness for applying marketing concepts in management of the school so as to prompts attention to the interest of all its legitimate stakeholders holding constituency to the market. The assumption of students being customers in higher education is echoed by a number of literatures. Hill [10], for example, discusses quality assurance in higher education and suggests that students are "primary customer" of higher education service where emphasis should be placed in the need to gather information on students' expectations. Others like Tasie [11] recommend universities to make every reasonable effort to satisfy students being customers and assess how well their needs are met with the application of total quality management (TQM). The study of Voss, Gruber and Szmigin [12] further illustrates the customer's nature of students, indicating that students want lectures to be "friendly"; valuable teaching experience means passing tests and engaging in preparation for students' vocational needs.

Contrary to Seeman and O'Hara [7], Singh [8] puts the arguments against students as customers. In his article, Singh [8] introduces and applies evaluation of teaching quality in higher education using aspects of Jurgen Habermas's critical theory of societal development as the evaluating stance. The article first explains the origin of SRT its relationship to Taylorism and TQM. The article then describes salient features of Habermas's model and its application and implication to higher education. The article proceeds to postulate that the spirit of "community, communicative action, and communicative rationality" is downplayed resulting in alienation of students and teachers. The article argues further that students and teachers are supposed to share the same stake, yet now have to engage in a process where one stakeholder (student) irrevocably evaluate the other (teacher), in 
Habermasian terms, constituting "a colonization of the academic life-world by the instrumentalism of an accounting-based practice” [8], or simply “accountingization” in Singh's term. The article concludes that SRT relegates students as passive recipients and encourages instant gratification; to rectify the situation and maintain quality in higher education, an approach that involves communicative action is required. Such approach should bring back students and teachers as "a community of scholars".

The strengths of the article lies in two aspects: First, the article adopted in-depth theoretical ground, coherent argument, with clear perspective which served as a great repercussion towards the current trend of the commodification of education. Besides, the article demonstrated that Habermas' conceptualization of societal change has much to offer in the field of organizational change in higher education. Despite the strengths, it is debatable whether using a Habermasian framework which is set at a societal level is valid to criticize a single modernist technique-SRT. While there are issues of SRT as identified by the article, it is also controversial whether these issues are significant enough for further pursuit. Further research directions should therefore include empirical evidence to support the claim that SRT has negative influence to the education sector.

In terms of stakeholder theory, the rejection of the proposal that students are being customers means the followings: First, higher education would no longer be associated with the positivist perspective of the marketization of higher education. Rather, the "colonization" of higher education is more fundamentally an issue which requires more thorough analysis to discover the nature of the root causes. Second, the success of management would now be primarily measured by how well school management interacts with such process of colonization which affects whether or not quality of education is substantiated. Third, stakeholders' welfare would no longer be accounted by single transactions or short term gains. Rather, relationship building efforts aiming at the long term welfare quality assurance based on multiple strands are to be considered for implementation. Fourth, stakeholders' constituency to the market is now neutrally shifted back to an education institute, hence, redefining the true meaning of concepts like "school”, "teacher" or "student” would help higher education management gain new insight on its managerial contour.

Contrary to Seeman and O’Hara and Singh, Sperlich and Spraul [7]-[9] attempt to define students as "active partners” of higher education. In the article, Sperlich and Spraul [9] explore different traditional concepts that explain the student-higher education institutions (HEI) relationship and make the suggestion that students are "active partners" of HEI. The article argues that students are to be conceptualized as "active partners" being on par with other partners and entitles to own a part of the organization. Such identity is constitutive of various identified identities of students such as "investor", "paying customer", "student", or "part of the scientific community". The article further proposes various means of efficient student relationships management for higher education. The article concludes that the concept of "active partner" can be transferred from original business setting to higher education management where different types of students are to be integrated into the concept; such integration contributes to the full potential of students and provides insight for various HEI managerial needs.

The strengths of the article lies in two aspects: First, it incorporates perspectives on the evaluation of students' objectives with empirical evidence (Germany). Besides, some interesting ideas of managing student relationships are presented. Despite its strengths, the concept of students as "active partners" lacks specificity and is devoid of content. That is to say, it cannot be operationalized in a way that allows scientific inspection or measurement of managerial success. Further, the concept tends to be vacuous and no decision-making criteria would adequately guide higher education management. Finally, farfetched analogy is observed as there is a blurry line as to determining whether or not students are "within" the community as "active partner"; it does not matter anyway where they are positioned but rather their actions and expectations. In connection with the above critique on Sperlich and Spraul [9], resemblances of stakeholder theory is discovered when students are viewed as "active partners": One can causally substitute the notion of "active partners" with "stakeholders" and find little obstacles in the elaboration and amplification of the same principles. So while the idea of "active partners" is interesting and covers a good theoretical breath, it is rather new content in old form and would inevitably fall into the manifold of weaknesses of stakeholder theory aforementioned.

Comparing the above three articles, it is noticed that, first, all these articles air a version of student's identity in good stand and have something to offer for higher education management. Second, stakeholder theory can coherently be applied to all the different versions of student's identity, yet the results elicited could be rather different if not insufficiently to be concluded. Third, none of the articles above conducted empirical research with which primary data were collected from students as to their own perceptions of identity. 


\section{Conclusion}

Providing multiple perspectives on the identity of students are observed, an enrichment of stakeholder theory catering student identity is necessary. The objective of the enrichment caters to the face that "stakeholder" being one solitary identity assigned should not categorically be accommodating various roles manifested. The direction of future research, thus, lies in three premises: First, the shaping and meaning of student identity will be examined by adopting social identity theory along with critical theory. The result of such examination should help construct a desired situation for higher education. Second, an empirical research will be carried out to look into the perception of students on their own identity. The data of such research should help outline an exemplar of the real situation in higher education. Third, by comparing the two results above, suggestions for better managerial approach for enhancing quality in higher education could be made. This in turns would allow a more comprehensive assessment of the higher education in relationship with the modern business environment; hence, better coexistence among various stakeholders along with better strategies for quality. In conclusion, whether it is because higher education feels the urge to compromise with the highly volatile modern business environment, thus, students naturally are placed in a position of being customers, and therefore a deformity of the traditional relationship, or students yearn for "experiences" outside the learning experience of the status quo, thus, aspiring a customer orientated, "satisfaction-guaranteed" package of educational service, is the core question for all stakeholders of higher education to reflect with imminent urgency.

\section{References}

[1] Borkowski, S.C. and Ugras, Y.J. (1992) The Ethical Attitudes of Students as a Function of Age, Sex and Experience. Journal of Business Ethics, 11, 961-979. http://dx.doi.org/10.1007/BF00871962

[2] Freeman, R. (1984) Strategic Management: A Stakeholder Approach. Ballinger, Boston.

[3] Rowley, T.J. (1997) Moving beyond Dyadic Ties: A Network Theory of Stakeholder Influences. Academy of Management Review, 22, 206-221.

[4] Donaldson, T. and Preston, L. (1995) The Stakeholder Theory of the Modern Corporation: Concepts, Evidence and Implications. Academy of Management Review, 20, 65-91.

[5] Key, S. (1999) Toward a New Theory of the Firm: A Critique of Stakeholder "Theory”. Management Decision, 37, 317-328. http://dx.doi.org/10.1108/00251749910269366

[6] Fassin, Y. (2008) Imperfections and Shortcomings of the Stakeholder Model's Graphical Representation. Journal of Business Ethics, 80, 879-888. http://dx.doi.org/10.1007/s10551-007-9474-5

[7] Seeman, E.D. and O’Hara, M. (2006) Customer Relationship Management in Higher Education: Using Information Systems to Improve the Student-School Relationship. Campus-Wide Information Systems, 23, 24-34. http://dx.doi.org/10.1108/10650740610639714

[8] Singh, G. (2002) Educational Consumers or Educational Partners: A Critical Theory Analysis. Critical Perspectives on Accounting, 13, 681-700. http://dx.doi.org/10.1006/cpac.2002.0552

[9] Sperlich, A. and Spraul, K. (2007) Students as Active Partners: Higher Education Management in Germany. The Innovation Journal: The Public Sector Innovation Journal, 12, Article 11.

[10] Hill, F.M. (1995) Managing Service Quality in Higher Education: The Identity of the Student as Primary Consumer. Quality Assurance in Education, 3, 10-21. http://dx.doi.org/10.1108/09684889510093497

[11] Tasie, G.O. (2010) Analytical Observations of the Applicability of the Concept of Student-as-Customer in a University Setting. Educational Research and Reviews, 5, 309-313

[12] Voss, R., Gruber, T. and Szmigin, I. (2007) Service Quality in Higher Education: The Identity of Student Expectations. Journal of Business Research, 60, 949-959. http://dx.doi.org/10.1016/j.jbusres.2007.01.020 
Scientific Research Publishing (SCIRP) is one of the largest Open Access journal publishers. It is currently publishing more than 200 open access, online, peer-reviewed journals covering a wide range of academic disciplines. SCIRP serves the worldwide academic communities and contributes to the progress and application of science with its publication.

Other selected journals from SCIRP are listed as below. Submit your manuscript to us via either submit@scirp.org or Online Submission Portal.
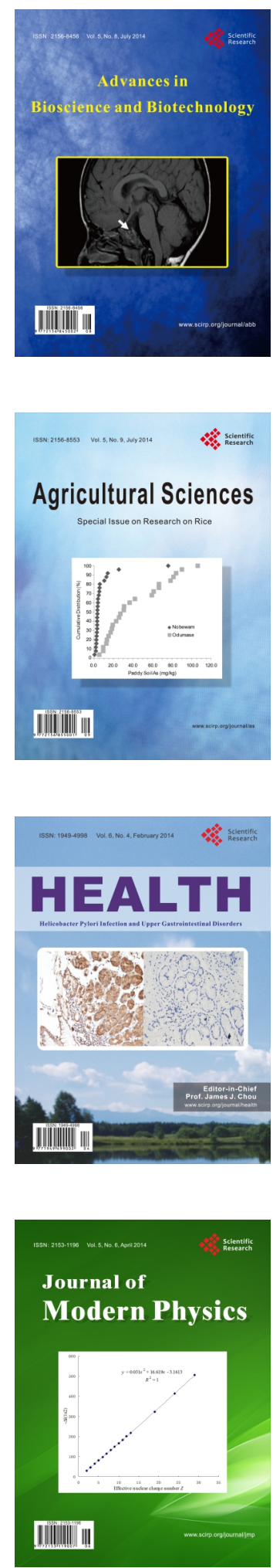
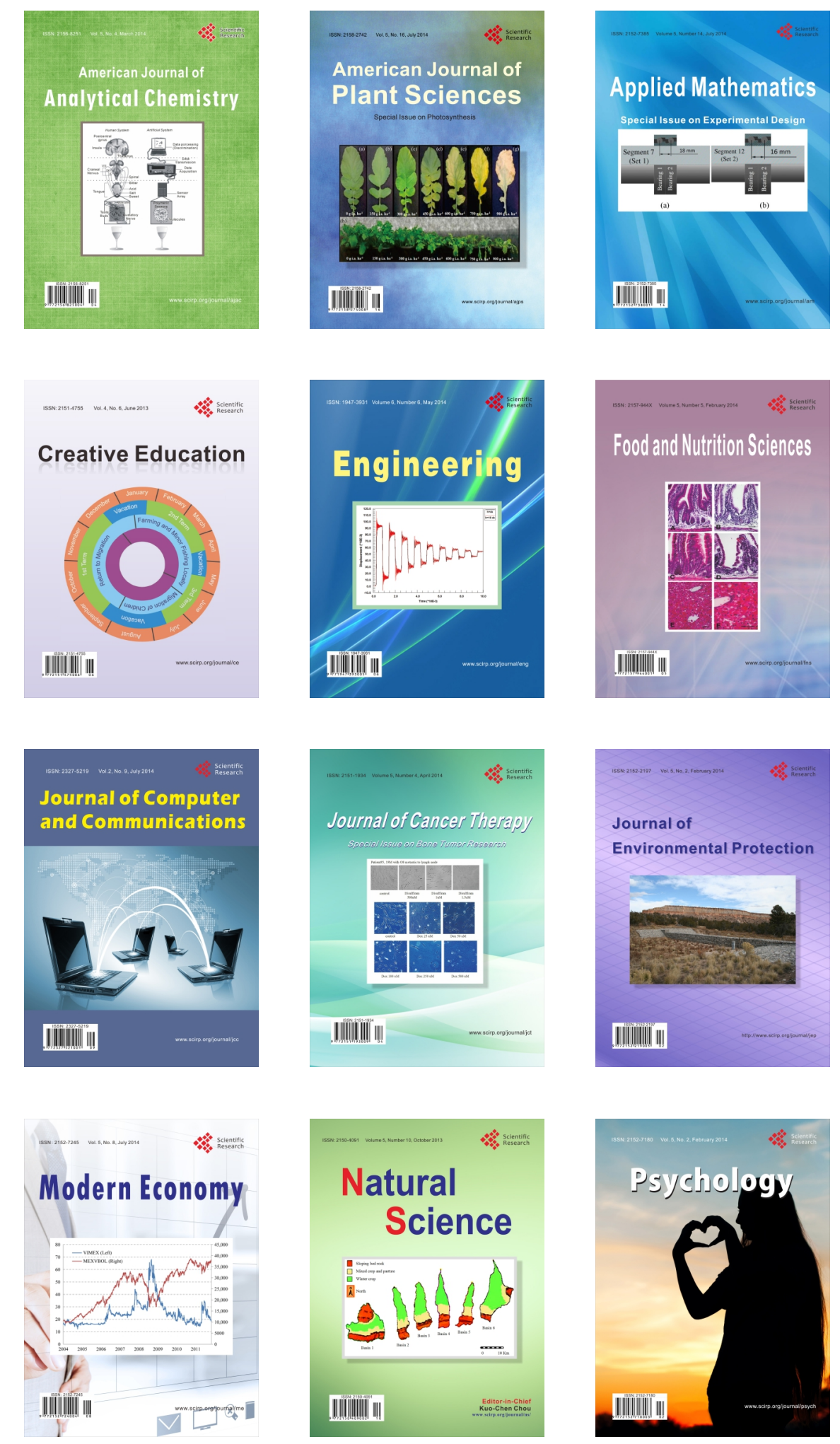